\title{
Acute Hepatitis Caused by Green Tea Infusion: A Case Report
}

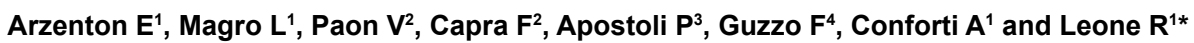 \\ ${ }^{1}$ Pharmacology Unit, Department of Public Health and Community Medicine, University of Verona, Verona, Italy \\ ${ }^{2}$ Section of Internal Medicine, Department of Biomedical and Surgical Science, University of Verona, Verona, Italy \\ ${ }^{3}$ Institute of Occupational Medicine and Industrial Hygiene, Department of Experimental and Applied Medicine, University of Brescia, Brescia, Italy \\ ${ }^{4}$ Department of Biotechnology, University of Verona, Verona, Italy
}

\begin{abstract}
The green tea is obtained by an unfermented process of leaves of Camellia sinensis and the main chemical components are polyphenols, particularly epigallocatechin-3-gallate and epicatechin-3-gallate that could be associated to adverse hepatic reactions. We present a case of acute hepatitis caused by the use of green tea. A 62-year-old woman was hospitalized because of the persistent high levels of liver function tests. After the hospitalization a lot of instrumental exams and blood checks were performed. The search of metallic elements in the used green tea infusions was performed using an inductively coupled-plasma mass spectrometry; high performance liquid chromatography-electro spray ionization-mass spectrometry analysis was done to characterize the metabolite profiles of the infusions of green tea. The blood check showed in particular alanine aminotransferase $(780 \mathrm{U} / \mathrm{L})$ and total bilirubin $(1.15 \mathrm{mg} / \mathrm{dL})$ levels abnormal. The abdominal echography and other blood parameters were normal, but liver biopsy described a "drug toxic damage". Every day over the previous 9 months the patient drank two or three cups of several brands of green tea infusions and she stopped this behavior when abdominal pain was persistent. Her medical history didn't report the use of other drugs or toxic products. After four months of stopping the use of green tea infusions, the liver function tests were normalized. The presence of metallic elements in tea infusion cannot justify the observed liver toxicity in our patient. Instead, the highest levels of epigallo catechin methyl gallate derived from epigallocatechin-3-gallate observed in one of the samples consumed by the patient, arise a possible correlation between some of the catechins in green tea and the hepatotoxic effect. It is conceivable that the mechanism of damage can be idiosyncratic-metabolic or allergic.
\end{abstract}

Keywords: Green tea; Acute hepatitis; Catechins

\section{Introduction}

The consumption of tea originated in China and Southeast Asia thousands of years ago and was thereafter introduced progressively all around the world. Tea is obtained from the leaves of Camellia sinensis. Its composition varies with climate, season, horticultural practices, variety and age of the plant, and manner in which the leaves have been processed [1]. The green tea is obtained by an unfermented process and the main chemical components of this type of tea are polyphenols, of which the main ones are catechins, mainly epigallocatechin-3gallate (EGCG, 5-12\%) and epicatechin-3-gallate (ECG, 1-5\%) [1]. The green tea is consumed both as an herbal supplement in tablets and as infuse using the "classic sachets" or directly with the dried leaves. Some studies have shown the potential health benefits associated with green tea consumption (e.g. reduction of risk of cardiovascular diseases and cancer) and these effects has been in part attributed to EGCG. But in the literature there are also several reports of adverse hepatic reaction associated to the green tea consumption $[1,2]$.

We present a case of a hepatic damage in a patient that consumed daily green tea infusion, we reported also the results of analysis of polyphenols and metallic elements in the used products.

\section{Case report}

A 62-year-old woman went to the First Aid Unit at G.B. Rossi University Polyclinic of Verona for the worsening of abdominal pain and nausea started two months before. She had no vomiting, diarrhea or fever. In this contest, the blood check showed alanine aminotransferase (ALT) level $780 \mathrm{U} / \mathrm{L}$ (reference range 6-40 U/L) and total bilirubin level $1.15 \mathrm{mg} / \mathrm{dL}$ (reference range $0.20-1.10 \mathrm{mg} /$ $\mathrm{dL}$ ). The abdominal echography didn't show pathological elements and other blood parameters were in the normal range. The patient's medical history didn't report anything relevant: tonsillectomy at 6 years old, appendectomy at 16 years old, cholecystectomy performed 30 years ago, two natural childbirths and hypercholesterolemia in diet therapy. She didn't use any drugs. The woman was discharged from First Aid with the advice to repeat the blood check. After ten days, her serum ALT level was $621 \mathrm{U} / \mathrm{L}$, serum alkaline phosphatase (ALP) level was $114 \mathrm{U} / \mathrm{L}$ (normal range 30-130 U/L), serum gamma glutamyl transferase (GGT) level was $110 \mathrm{U} / \mathrm{L}$ (normal range less than $33 \mathrm{U} / \mathrm{L}$ ), ferritin level was $1011 \mu \mathrm{g} / \mathrm{L}$ (normal range 30-250 $\mu \mathrm{g} / \mathrm{L}$ ), serum iron level was $189 \mu \mathrm{g} / \mathrm{dL}$ (normal range 37-145 $\mu \mathrm{g} / \mathrm{dL}$ ) and markers for HBV and HCV were negative. After a month from admission at First Aid, she was hospitalized because of the persistent high levels of liver function tests. During the hospitalization these exams were performed: abdominal echography was negative, serum ALT 365 U/L, AST 178 U/L (reference range 6-44 U/L), ALP $113 \mathrm{U} / \mathrm{L}$, GGT $109 \mathrm{U} / \mathrm{L}$, total bilirubin $1.41 \mathrm{mg} / \mathrm{dL}$, ferritin $939 \mu \mathrm{g} / \mathrm{L}$, serum iron $218 \mu \mathrm{g} / \mathrm{dL}$, and non organ-specific autoantibodies (ANA, ENA, ASMA, AMA, LKM) were negative. A detailed history revealed that the patient drank two or three cups of green tea infusion every day over the previous 9 months and

*Corresponding author: Roberto Leone, Department of Public Health and Community Medicine, Pharmacology Unit, University of Verona, LA Scuro 10, 37134 Verona, Italy, Tel: +39 0458124706; Fax: +39 0458124876; E-mail: roberto.leone@univr.it

Received November 14, 2014; Accepted November 30, 2014; Published December 03, 2014

Citation: Arzenton E, Magro L, Paon V, Capra F, Apostoli P, et al. (2014) Acute Hepatitis Caused by Green Tea Infusion: A Case Report. Adv Pharmacoepidemiol Drug Saf 3: 170. doi:10.4172/2167-1052.1000170

Copyright: (c) 2014 Arzenton E, et al. This is an open-access article distributed under the terms of the Creative Commons Attribution License, which permits unrestricted use, distribution, and reproduction in any medium, provided the original author and source are credited. 
she stopped this habit when abdominal pain was persistent. The brands of green tea were of several types. She denied the use of other drugs or products (e.g. wine, herbal or narcotic products). Thanks to the clinical improvement the patient was discharged after twelve hospitalization days. The liver biopsy performed in the patient showed a "drug toxic damage", characterized by a hepatocellular confluent necrosis in zone 3 of hepatic acinus in perivenular area.

After four months of stopping the use of green tea infusions, the liver function tests were normalized and ferritin was reduced: ALT 26 U/L, AST $28 \mathrm{U} / \mathrm{L}$, ALP $84 \mathrm{U} / \mathrm{L}$, GGT $26 \mathrm{U} / \mathrm{L}$, total bilirubin $0.68 \mathrm{mg} /$ $\mathrm{dL}$, ferritin $324 \mu \mathrm{g} / \mathrm{L}$, serum iron $161 \mu \mathrm{g} / \mathrm{dL}$ (Figure 1 for ALT trend).

After the hospitalization the presence of metallic elements and catechins in the different brands of green tea consumed by the patient was performed using appropriated techniques.

\section{Methods and Results of Metallic Elements Analysis}

The concentrations of the following metallic elements: aluminium (Al), antimony $(\mathrm{Sb})$, arsenic (As), barium $(\mathrm{Ba})$, cadmium $(\mathrm{Cd})$, chromium $(\mathrm{Cr})$, cobalt $(\mathrm{Co})$, copper $(\mathrm{Cu})$, iron $(\mathrm{Fe})$, lead $(\mathrm{Pb})$, lithium $(\mathrm{Li})$, manganese $(\mathrm{Mn})$, mercury $(\mathrm{Hg})$, molybdenum $(\mathrm{Mo})$, nickel $(\mathrm{Ni})$, rubidium $(\mathrm{Rb})$ selenium $(\mathrm{Se})$, strontium $(\mathrm{Sr})$, thallium $(\mathrm{Tl})$ and zinc $(\mathrm{Zn})$, was evaluated by inductively coupled plasma mass spectrometry (ICP-MS). This is one of the most sensitive analytical techniques for single element measurement in biological and non biological matrices and enables rapid multi-element determinations. In addition it is one of the few analytical technique for isotopic analysis of elements [3-5]. ICP-MS is the combination of an inductively coupled plasma with a quadrupole mass spectrometer, which, similarly to monochromator in AAS or ICP-AES systems, separates ions according to their mass-

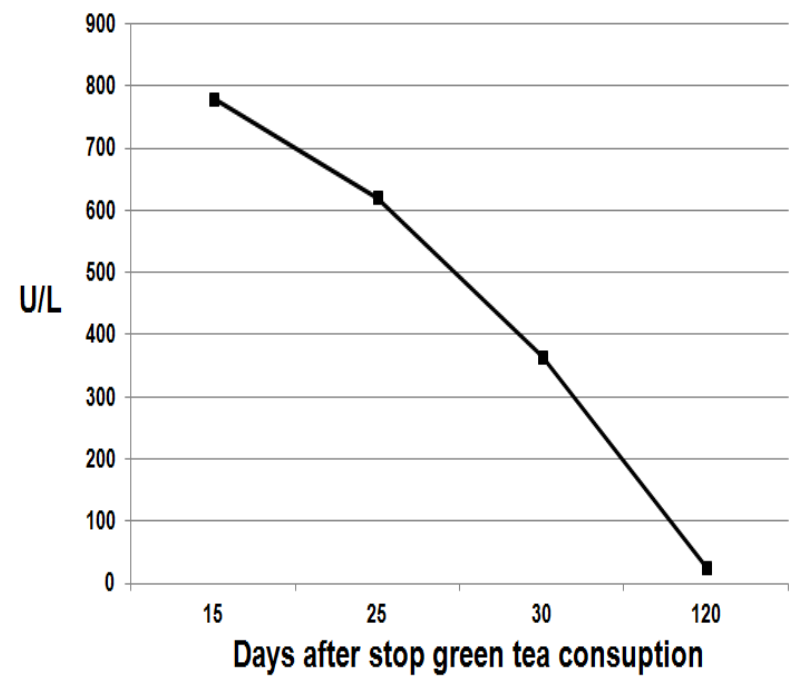

Figure 1: Alanine aminotransferase trend after stop green tea consumption. to-charge ratio. Samples have been prepared from four batches of green tea used by the patient. Commercial water was used to obtained tea infusions; so the concentration of metallic elements was also determined in this water. Samples underwent ICP-MS analysis on a Perkin Elmer ELAN DRC II instrument (Perkin Elmer Sciex, Woodbridge, ON, Canada) using the analytical technique total quant with external calibration. For each sample, two runs were performed (two replicates each), with and without dynamic reaction cell (DRC) [6]. The coefficients of variation ranged from 4 to $8 \%$ among series and from 6 to $12 \%$ between series. The instrument was calibrated using standard solution at a concentration of $10 \mu \mathrm{g} / \mathrm{L}$ (Multielement ICP-MS Calibration Standard 3, Matrix per Volume: 5\% HNO3 per $100 \mathrm{~mL}$, Perkin Elmer Plus).

The concentrations of the metallic elements in tea samples are shown in Table 1. Our results showed that the concentration of metallic elements in the drinkable water are low, anyway within the Italian decree recommended limit values (D.Lgs. Governo $n^{\circ} 31$ 02/02/01). Furthermore it can been seen the concentrations of some metallic elements $(\mathrm{Al}, \mathrm{Pb}, \mathrm{Mn}, \mathrm{Ni}, \mathrm{Rb}, \mathrm{Sr}, \mathrm{Zn})$ in the tea samples are much higher than the concentrations of the same metallic elements in the water used for tea infusions.

\section{Detection and Results of Catechin Analysis}

Green tea infusions have been prepared from four batches of green tea used by the patient plus other additional 3 batches purchased from the local market, pouring $50 \mathrm{ml}$ of hot water $\left(80^{\circ} \mathrm{C}\right)$ on $0.5 \mathrm{mg}$ of tea leaves; after 5 minutes the infusions were centrifuged for $10 \mathrm{~min}$ at $16,000 \mathrm{~g}$ at $4^{\circ} \mathrm{C}$ and filtered through $0.2 \mu \mathrm{m}$ pore filters. The Figure 2 shows the different amount of polyphenols of the green tea consumed by the patient, in particular it shows a major amount of acid gallic catechins, especially the EGCG (red peak).

The metabolite profiles of the extracts were obtained by reversed phase high performance liquid chromatography-electro spray ionization-mass spectrometry (HPLC-ESI-MS) with $5 \mu$ l of injection volume, as described by Cavallini and collaborators [7]. Metabolites were identified through the comparison of $\mathrm{m} / \mathrm{z}$, retention time and fragmentation pattern with those of authentic standards and, when authentic standards were not available, comparing $\mathrm{m} / \mathrm{z}$ and fragmentation patterns with those reported in the literature. Chromatogram data extraction and alignment were carried out using MZmine software (http://mzmine.sourceforge.net). Epicatechin, quercetin, procyanidin B1 and caffeic acid (Extrasyntese, sas, France) was used as external standards.

For flavan-3-ols, hydroxycinnamic acids, procyanidins and other flavonoids quantitation, calibration curves of the above standard compounds were used. Consequently, the flavan-3-ols were quantified as $\mathrm{mg}$ of epicatechin equivalents, the procyanidins as $\mathrm{mg}$ of procyanidin B1 equivalents, coumaric, caffeic and gallic acid as mg of caffeic acid equivalents and the other flavonoids as $\mathrm{mg}$ of quercetin equivalents. Since no standards were used for alkaloids, they were expressed as intensity of the correspondent peak area (arbitrary units).

\begin{tabular}{|c|c|c|c|c|c|c|c|c|c|c|c|c|c|c|c|c|c|c|c|c|c|c|c|}
\hline & $\mathbf{M n}$ & $\mathbf{A l}$ & $\mathbf{R b}$ & $\mathbf{Z n}$ & $\mathbf{S r}$ & $\mathbf{C u}$ & $\mathbf{N i}$ & $\mathbf{F e}$ & $\mathbf{B a}$ & $\mathbf{P b}$ & $\mathbf{C o}$ & $\mathbf{L i}$ & $\mathbf{H g}$ & $\mathbf{C r}$ & $\mathbf{A s}$ & $\mathbf{S e}$ & $\mathbf{T I}$ & $\mathbf{C d}$ & $\mathbf{S b}$ & $\mathbf{M o}$ \\
\hline Sample 1 & 2626,5 & 1837,5 & 336,4 & 143,0 & 101,4 & 73 & 54,6 & 43,0 & 32,0 & 3,9 & 1,7 & 0,8 & 0,69 & 0,6 & 0,4 & 0,3 & 0,2 & 0,10 & 0,1 & 0,07 \\
\hline Sample 2 & 1032,5 & 1457,5 & 639,4 & 121,0 & 86,4 & 53 & 40,6 & 2,0 & 6,0 & 3,1 & 0,6 & 0,2 & 0,04 & 0,0 & 0,2 & $-0,1$ & 0,1 & 0,05 & 0,0 & 0,06 \\
\hline Sample 3 & 1530,5 & 1488,5 & 296,4 & 82,0 & 99,4 & 41 & 44,6 & 64,0 & 15,0 & 2,4 & 1,4 & 0,2 & 0,79 & 0,8 & 0,2 & 0,1 & 0,3 & 0,05 & 0,0 & 0,11 \\
\hline Sample 4 & 1530,5 & 654,5 & 488,4 & 87,0 & 98,4 & 18 & 21,6 & 10,0 & 5,0 & 2,1 & 1,1 & 0,3 & 0,19 & 0,0 & 0,0 & 0,2 & 0,4 & 0,05 & 0,0 & 0,10 \\
\hline $\mathbf{H}_{\mathbf{2}} \mathbf{O}$ & 0,5 & 1,5 & 0,6 & 1,0 & 14,6 & - & 0,4 & 24,0 & 27,0 & 0,2 & 0,1 & 1,1 & 0,0 & 0,4 & 0,3 & 0,3 & - & & 0,3 & 0,15 \\
\hline
\end{tabular}

Table 1: Metallic elements content ( $\mu \mathrm{g} / \mathrm{L}$, room temperature) in tea aqueous infusions (net value) and in the water used for infusions. 
Citation: Arzenton E, Magro L, Paon V, Capra F, Apostoli P, et al. (2014) Acute Hepatitis Caused by Green Tea Infusion: A Case Report. Adv Pharmacoepidemiol Drug Saf 3: 170. doi:10.4172/2167-1052.1000170
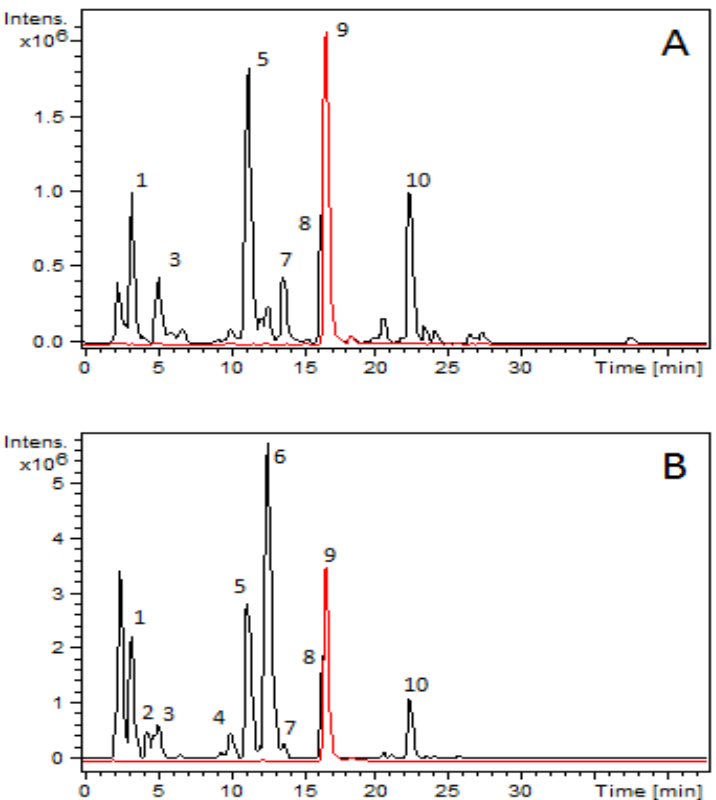

\begin{tabular}{|c|c|c|c|c|}
\hline id & $\mathrm{rt}$ & $\mathrm{m} / \mathrm{z}(-)$ & $\mathrm{m} / \mathrm{z}(+)$ & putative identification \\
\hline 1 & 3,4 & 343 & 345 & galloyl quinic acid \\
\hline 2 & 4,5 & & 166 & phenylalanine \\
\hline 3 & 5,2 & 305 & 307 & gallocatechin \\
\hline 4 & 10,1 & & 365 & unidentified \\
\hline 5 & 11,4 & 305 & 307 & epigallocatechin \\
\hline 6 & 12,7 & & 195 & caffeine \\
\hline 7 & 13,8 & 353 & 355 & caffeoyl quinic acid \\
\hline 8 & 16,3 & 289 & 291 & epicatechin \\
\hline & & & 459 & $\begin{array}{c}\text { epigallocatechin-3- } \\
\text { gallate }\end{array}$ \\
\hline 9 & 16,7 & 457 & 459 & epicatechin-3-gallate \\
\hline 10 & 22,3 & 441 & 443 &
\end{tabular}

Figure 2: Chromatograms in negative $(A)$ and positive $(B)$ ionization modes; the mass to charge ratio $(\mathrm{m} / \mathrm{z}$ ), the retention time (in minutes) and the putative identification of the main peaks are shown.

The HPLC-ESI-MS analysis of the green tea infusions allowed to detect 81 signals, corresponding to 49 metabolites, their fragments and adducts, and 16 unidentified signals [8]. The 49 metabolites included hydroxycinnamic acids (coumaric and caffeic acid derivatives), gallic acid derivatives, flavan-3-ols, procyanidins, other flavonoids and two alkaloids (caffeine and theobromine). The main metabolites are shown in the chromatograms of Figure 3.

The metabolite profiles of the infusions of the four green teas used by the patient were almost totally in line with those of three samples purchased from the markets. No significant differences were observed between the unidentified metabolites between the two groups of samples (not shown).The only remarkable anomaly was the higher levels of the epigallocatechin-methyl-gallate (methylated flavan-3-ol), observed in the sample two, one of those consumed by the patient, compared with all the other samples.

\section{Discussion}

Green tea, as many other herbal products, is not adequately tested for its pharmacology, safety and toxicology. In the literature some articles mention how green tea catechins, especially EGCG, are considered to be associated with an anti-cancer, anti-obesity, anti-atherosclerotic and anti-dental caries activity [9-11]; however the benefits of green tea are
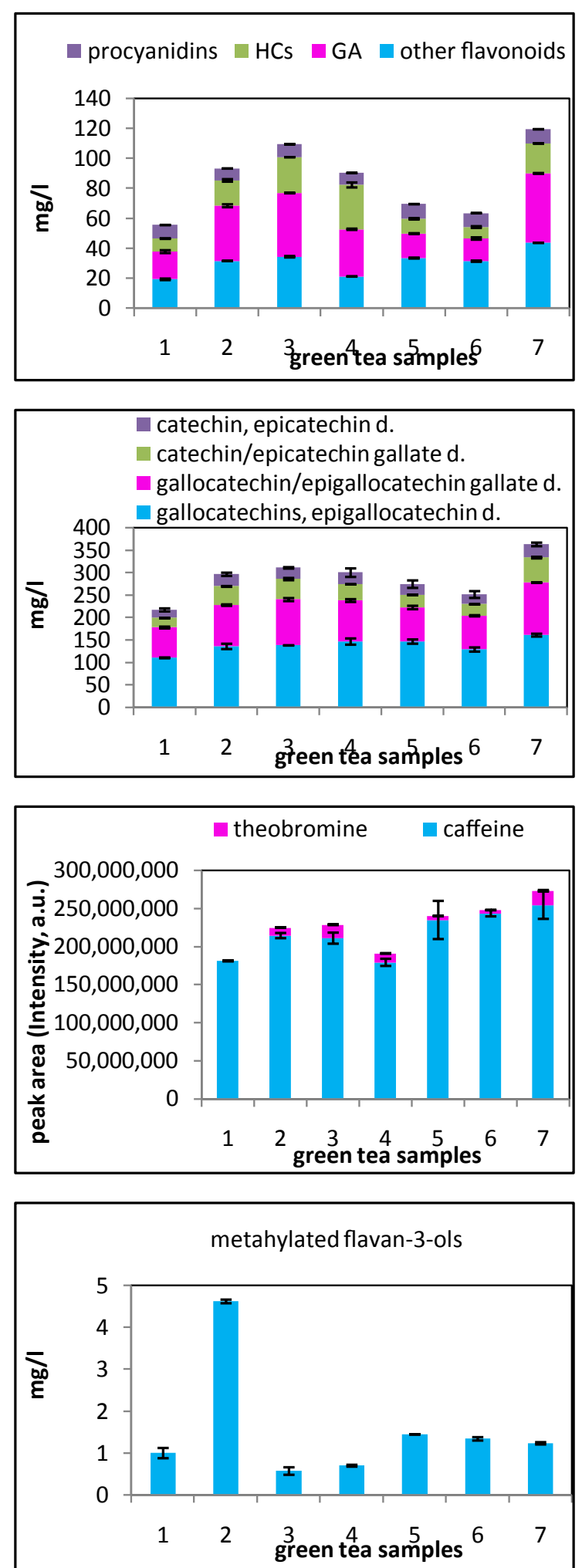

Figure 3: Determination of flavan-3 ols, methylated flavan-3-ols, procyanidins, other flavonoids, alkaloids, coumaric, caffeic and gallic acid derivative in seven gree tea samples. From 1 to 4: the green tea consumed by the patient. From 5 to 7: green tea purchases at local market. $d .=$ derivatives, $a . u=a r b i t r a r y ~ u n i t s$. 
not well established and unclear scientific evidence are still reported for its use in these specific conditions [12,13]. On the other hand tea is the most consumed beverage in the world, aside the water and also green tea has been very marketed during recent years. Its use has increased also on the theoretical basis of its potential health care effects. Consequently to this wide-spread and increase of use several cases of hepatotoxicity following the consumption of dietary supplements containing green tea have been reported. In April 2003 French and Spain authorities suspended market authorization of Exolise (Arkopharma, Carros, France), a weight loss supplement containing a green tea extract, following 13 cases (nine in France and four in Spain) of liver damage due to its consumption [14]. The estimated frequency of this adverse effect was, according to Sarma and collegues, 1 case per 100,000 boxes of Exolise sold from 1999 to 2003 [15].

In this paper we present a case of a hepatic damage in a patient that consumed daily green tea infusion. The liver biopsy showed a "drug toxic damage", characterized by a hepatocellular confluent necrosis in zone 3 of hepatic acinus in perivenular area. In our view there are important elements to suggest a probable association between green tea and hepatotoxicity according the Naranjo score [16]:

1. in the literature there are many other similar cases $[1,2]$,

2. the reported hepatotoxic reaction showed a temporal relationship between the use of green tea preparations and the onset of the effects,

3. the reaction has been improved after the withdrawal of the product,

4. non-drug-related causes (viral infections, alcohol and other supplement products) were excluded,

5. in the anamnesis the patient did not report any other concomitant drugs,

6. the presence of the hepatic damage has been confirmed by haematological and instrumental exams.

We also analyzed the composition of the different brands of green tea consumed by the patient, in particular we evaluated the concentrations of metallic elements and catechins.

The main reasons we focalized our analysis on the metallic element's detection are that some articles have indicated in the green tea the presence of metals [17] and that some of them, especially the heavy ones such as $\mathrm{As}, \mathrm{Cd}, \mathrm{Cr}, \mathrm{Cu}, \mathrm{Pb}, \mathrm{Hg}$, and $\mathrm{Mn}$, in case of acute exposure can cause hepatotoxic effects $[18,19]$. As supposed, we found the presence in the green tea samples of several metallic elements, however in concentrations below the human levels of toxicity $[19,20]$; it is important to underline that for rubidium, in particular on its hepatotoxicity, the safety information are limited.

The observed different metallic element content between the various sample depends from the different green tea geographical origin. In fact, Fernandez and colleagues described the differentiation of Camellia sinensis varieties and their geographical origin according to their metal content. The metal amount of 46 tea samples, including green, black and instant teas, was analyzed. Potassium, calcium, magnesium, aluminium and manganese were the metal with the major quantity. Aluminium and manganese have average contents of 1074.0 $\mathrm{mg} / \mathrm{Kg}$ and $824.8 \mathrm{mg} / \mathrm{kg}$ respectively. The authors conclude that metal parameters are good chemical descriptors to recognize the country of origin of tea samples [17].

Our results showed that only small amount of hepatotoxic heavy metals may get into the aqueous extract, while the higher contents remain insoluble in the solid leaves during beverage preparation.

On the contrary, the infusions and aqueous extracts, used by our patient to prepare the tea, permit to extract polar and hydrophilic substances as catechins are. The catechin more abundant was the EGCG, as shown in the Figure 2 (red peak). With regard to the metabolites the only remarkable anomaly was the higher levels of epigallocatechinmethyl-gallate derived from the EGCG, observed in the sample two, one of those consumed by the patient.

To put this into a practice perspective a cup of green tea can provide about $80-106 \mathrm{mg}$ of polyphenols, of which catechins are the most representative. The roughly equivalent of three cups of tea, corresponding to our daily patient's habit, is about $375 \mathrm{mg}$ catechins, of which 270 is EGCG [15].

In the literature there are many similar cases [1,2] and the hepatotoxic role of EGCG and its metabolites has been well described both in animals and humans:

1. the predominant green tea catechin (EGCG) was identified as ten times more cytotoxic to isolated rat hepatocytes in vitro than other minor catechins (LD50 $91.6 \mathrm{microg} / \mathrm{mL}$ for EGCG) [21];

2. high doses of EGCG has been associated with extensive liver necrosis in animals [22,23];

3. in rats the administration of $500 \mathrm{mg} / \mathrm{kg}$ per day EGCG for 13 weeks increased bilirubin and decreased fibrinogen, while a single dose of $2000 \mathrm{mg} / \mathrm{kg}$ EGCG by the oral route was toxic [24];

4. Goodin and collaborators found that Swiss Webster mice female are more susceptible than males to EGCG toxicity and in our case the patient was a woman [23]. Also in the article of Mazzanti et al. most of the case reports of green tea hepatotoxicity involved woman [1];

5. cytotoxic of EGCG was shown in cultured human hepatic stellate cells [25];

6. Mazzanti et al. performed a literature search of publication between 1999 and October 2008 and found 34 cases of hepatitis. The histological examination of the liver revealed inflammatory reactions, cholestasis, occasional steatosis and necrosis. In two unpublished cases the authors suggest a casual association between green tea and liver probably due to EGCG or its metabolites [1];

7. in a systematic review by the US Pharmacopeia from January 1966 and June 2007 in Pubmed a total of 216 case reports on green tea products were analyzed, including 34 reports concerning liver damage, the same result of Mazzanti and colleagues [1]. The authors in the conclusion presented the hepatotoxic role of EGCG [15].

The mechanism of the hepatic toxicity of green tea is unclear. A study looking into the cytotoxic of green tea extract on rat hepatocytes was unable to understand if EGCG has toxic effects at plasma levels higher than those achieved in human pharmacokinetics studies [22]. Therefore, considering also that the concentration achieved in humans by these metabolites is low, it is conceivable that the mechanism of damage could be idiosyncratic-metabolic or immuno-allergic [22,23].

\section{Conclusion}

A probable hepatic reaction from green tea has been suggested. The hepatotoxicity can be imputed to EGCG and its metabolites, while the metallic elements are not involved. Furthermore considering how genetic factors could be important in modulating susceptibility 
Citation: Arzenton E, Magro L, Paon V, Capra F, Apostoli P, et al. (2014) Acute Hepatitis Caused by Green Tea Infusion: A Case Report. Adv Pharmacoepidemiol Drug Saf 3: 170. doi:10.4172/2167-1052.1000170

Page 5 of 5

to green tea, a more receptiveness for women may be hypothesised. The mechanism is unclear, however taking into account the low bioavailability of EGCG, an idiosyncratic-metabolic or immunoallergic cannot be excluded.

\section{References}

1. Mazzanti G, Menniti-Ippolito F, Moro PA, Cassetti F, Raschetti R, et al. (2009) Hepatotoxicity from green tea: a review of the literature and two unpublished cases. Eur J Clin Pharmacol 65: 331-341.

2. Jimenez-Saenz M, Martinez-Sanchez Mdel C (2006) Acute hepatitis associated with the use of green tea infusions. J Hepatol 44: 616-617.

3. Murphy KE, Beary ES, Rearik MS, Vocke RD (2000) Isotope dilution inductively coupled plasma mass spectrometry (ID ICP-MS) for the certification of lead and cadmium in environmental standard reference materials. Fresenius $\mathrm{J}$ Anal Chem 368: 362-370.

4. Becker JS, Dietze HJ (2000) Precise and accurate isotope ratio measurements by ICP-MS. Fresenius J Anal Chem 368: 23-30.

5. Apostoli $P(2002)$ Elements in environmental and occupational medicine. J Chromatogr 778: 63-97.

6. Apostoli P, De Palma G, Catalani S, Bortolotti F, Tagliaro F (2009) Multielementa analysis of tissues from Cangrande della Scala, Prince of Verona, in the 14th century. J Anal Toxicol 33: 322-327.

7. Cavallini E, Zenoni S, Finezzo L, Guzzo F, Zamboni A, et al. (2014) Functional Diversification of Grapevine MYB5a and MYB5b in the Control of Flavonoid Biosynthesis in a Petunia Anthocyanin Regulatory Mutant. Plant Cell Physio 55: 517-534.

8. Del Rio D, Stewart AJ, Mullen W, Burns J, Lean ME, et al. (2004) HPLC-MSn analysis of phenolic compounds and purine alkaloids in green and black tea. $\mathrm{J}$ Agric Food Chem 52: 2807-2815.

9. Suzuki Y, Miyoshi N, Isemura M (2012) Health-promoting effects of green tea. Proc Jpn Acad Ser B Phys Biol Sci 88: 88-101.

10. Cabrera C, Artacho R, Gimènez R (2006) Beneficial Effects of Green Tea - A Review. J Am Coll Nutr 25: 79-99.

11. Forester SC, Lambert JD (2011) The role of antioxidant versus pro-oxidant effects of green tea polyphenols in cancer prevention. Mol Nutr Food Res 55 : 844-854.

12. Ulbricht CE, Basch EM, Mosby E (2005) Natural Standard-Herb \& Supplement Reference- Evidence Based Clinical Reviews.
13. Jurgens TM, Whelan AM, Doucette S, Kirk S, Foy E (2012) Green tea for weight loss and weight maintenance in overweight or obese adults. Cochrane Database Syst Rev.

14. Gloro R, Hourmand-Ollivier I, Mosquet B, Mosquet L, Rousselot P, et al. (2005) Fulminant hepatitis during self-medication with hydroalcoholic extract of green tea. Eur J Gastroenterol Hepatol 17: 1135-1137.

15. Sarma DN, Barrett ML, Chavez ML, Gardiner P, Ko R, et al (2008) Safety of green tea extracts: a systematic review by the US Pharmacopeia. Drug Sa 31: 469-484.

16. Naranjo CA, Busto U, Sellers EM, Sandor P, Ruiz I, et al. (1981) A method for estimating the probability of adverse drug reactions. Clin Pharmacol Ther 30 239-245.

17. Fernández-Cáceres PL, Martín MJ, Pablos F, González AG (2001) Differentiation of tea (Camellia sinensis) varieties and their geographical origin according to their metal content. J Agric Food Chem 49: 4775-4779.

18. García-Niño WR and Pedraza-Chaverrí J (2014) Protective effect of curcumin against heavy metals-induced liver damage. Food Chemical Toxicology 69 182-201.

19. http://www.micromedexsolutions.com/micromedex2/librarian/

20. Safe Drinking Water Committee (1982) Drinking Water and Health Washington DC: The National Academies Press.

21. Galati G, Lin A, Sultan AM, O'Brien PJ (2006) Cellular and in vivo hepatotoxicity caused by green tea phenolic acids and catechins. Free Radic Biol Med 40: 570-580.

22. Schmidt M, Schmitz HJ, Baumgart A, Guédon D, Netsch MI, et al. (2005) Toxicity of green tea extracts and their constituents in rat hepatocytes in primary culture. Food Chem Toxicol 43: 307-314

23. Goodin MG and Rosengren RJ (2003) Epigallocatechin gallate modulates CYP450 isoforms in the female Swiss-Webster mouse. Toxicol Sci 76: 262270.

24. Isbrucker RA, Edwards JA, Wolz E, Davidovich A, Bausch J (2006) Safety studies on epigallocatechin gallate (EGCG) preparations. Part 2: dermal, acute and short-term toxicity studies. Food Chem Toxicol 44: 636-650.

25. Chen A, Zhang L, Xu J, Tang J (2002) The antioxidant (-)-epigallocatechin3-gallate inhibits activated hepatic stellate cell growth and suppresses acetaldehyde-induced gene expression. Biochemical J 368: 695-704. 